\title{
Collaborative Governance and Infrastructure Development in Indonesia: A Review
}

\author{
Dwi Agus Prasetyo \\ The Ministry of Industry, Indonesia
}

INFORMASI ARTIKEL

Article history:

Data submission : 12 September 2018

$1^{\text {st }}$ revision: 10 January 2019

Accepted: 17 April 2019

Available online: 02 May 2019

Keywords: collaborative governance, infrastructure development, Indonesia

\begin{abstract}
Collaboration in public sector are a common concept. Its implementation is solely used to tackle the problem in public sector issues which often require all stakeholder to participate in oreder to achieve common goal without endanger every other stakeholder goals, and also to efficiently handle the issues that can only be solved by merge all resources from every stakeholder in the matter. In infrastructure development in Indonesia, often the issues are regarding the split allocation resource and authority that possessed by every stakeholder. This often worsen the development and need the approach of collaboration in which offered by collaborative governance in general. In the attempt to improve the infrastructure development in Indonesia, collaborative governance might be the best solution as of now if we investigate the general concept of collaborative governance and the state of the issue of infrastructure development in Indonesia.
\end{abstract}

2019 FIA UB. All rights reserved.

\section{Introduction}

Infrastructure development in Indonesia as the backbone of development process put infrastructure development in higher regards among others project in Indonesia. Due to this demand regarding infrastructure development, there are a lot of new scheme being implemented to meets this demand in the last decade, namely; PPP (Public-Private Partnership), cross boundaries institution scheme e.g. special economic zone, industry zone, tourism destination that coordinates the scatter authorities across ministry and government level etc. The whole scheme based its mechanism in coordination among the stakeholders whether it is government organization, NGO, and community. This scheme being so popular lately due to its possession in potential solution for solving public sector issues.

The demand of collaboration are increases and force the scholars and practitioners to investigate further regarding this so-called collaboration. Many schollars have mentioning this phenomenon in public sector and most of them reffer this as collaborative governance. Ansell and Gash (2007) reffer the collaborative governance as the type of governance in which public and private actors work collectively in distinctive ways, using processes to establish laws and rules for the provision of public goods. They also mention the model of collaborative governance that pin-point four variables namely, (1) starting condition, (2) institutional design, (3) facilitative leadership, (4) and collaborative process that mainly affecting collaboration in a way to achieving the common goals. Apart from that, there are three key indicators that played a high role in this model that identified as the most important namely, (1) time, (2) trust, and (3) interdependence. They emphasize directly that this key indicators as the most needed for the collaboration to achieve of what its excpected from.

As the statement of importance has been made in the first part of this paper, we conclude that it is needed to examine further regarding this scheme, infrastructure development, and its relevance in this issue. To identify first stages of what it does regarding infrastructure development in Indonesia. To conclude, the second part of this paper will be discussed regarding collaborative 
governance and infrastructure development in Indonesia in brief.

\section{Disccussion}

Demands that public sector have faced today are more complicated than ever. Nowdays public sector issue may trigger more complex issue as Forrer et. al. (2014) reffer as "a densely interconnected system in which local decisions and actions may trigger global repercussions - and vice versa-and the fate of communities in one region is bound to choices by decision makers elsewhere". This problematic issue aligns with Purra (2011) explanation regarding Indonesia's structure of authority in infrastructure development, "There are inefficiency arrangement in infrastructure development in Indonesia in which splits the allocation of responsibilities and authorities among the ministry and thus provide no co-ordination, leadership, expertise of the plan, and project execution". Now we can illustrate how messed the mechanism of infrastructure development in Indonesia starting by its institution structure, worsen by the problematic phenomenon that caused by other institution issue. For simple explanation, providing the pavement of city streets that collide with fiber optic infrastructure and water supply, there are a lot of cases which there are no integrated plan and execution of plan that worsen the state of the infrastructure (in this case the newly paved street). Not to mention to achieve our national infrastructure competitiveness index, for only sustaining the exist infrastructure would be very tricky job for the charged institution.

Forrer et. al. (2014) identify the effort to settle the issue as the cross-sector collaboration. Cross-sector collaboration are voluntary, includes public sector, private sector, and non-profit sector in the process and all this collaboration are held to achieve common goals. In management theory (Agranoff and McGuire, 2003), the idea of principle that managers often must operate across organizations as well as within hierarchies is becoming an accepted component. This includes the work of governments connecting with other governments and with the nongovernmental sector. Through partnerships, networks, contractual relationships, alliances, committees, coalitions, consortia, and councils, managers in public and private agencies jointly develop strategies and produce goods and services on behalf of their organizations. Although in collaborative management are focused on the idea engaging in more than one forum to achieve the goal, the idea of collaboration that need more than just a mere meeting to settled problem, indicates that the idea of its collaboration itself work beyond just working together.
Finally, the concept of collaboration that more suitable to the issues in public sector are goes by the name of collaborative governance. Zadek (2006) ilustrate the need of collaboration as follows, "partnerships involving public institutions, and private commercial and civil society organizations, underpin a growing number of initiatives addressing issues as diverse as HIV/AIDS, labor standards, obesity, and corruption, and the delivery of public services from education to traffic systems to safe and civilized prisons." The demand of collaboration that inclusivelly include all stakeholder are requiring to tackle the sort of issues that so complex, bound to all level of community and institution that for one attempt of solving are imposible without other party or stakeholder.

Apart from Zadek's explanation there are Ansell and Gash (2007) who established model of collaborative governance derived from succesive approximation from 137 cases. Their findings are on the first stages are conclude that collaborative governance is type of governance in which public and private actors work collectively in distinctive ways, using processes to establish laws and rules for the provision of public goods. If we were to merge with Zadek's idea, all of Ansell and Gash's explanation are done with deliberative way, means all parties are deliberatively engage in the matter with one ultimate common goal. In the model of Ansell and Gash's, there are four variables, (1) starting conditions, (2) institutional design, (3) facilitative leadership, (4) collaborative process.

Those four variables bound to Indonesia's key issues of infrastructure development. As previously mention, first issue of infrastructucure development in Indonesia was the split allocation of authority among the ministry whom charge with infrastructure development. This issue relates closely with institutional design in Ansell and Gash's model. The issue of split allocation of authorities often made the institution are hard to work together, especially with party's that might prolong their time of project. The complex allocation of the authorities also made the relationship among them are a bit complicated which bound to the other variables in model of collaborative governance; starting condition. Lack of figures of leadership that can create bond in the forum of collaboration also made it more complicated in infrastructure development in Indonesia. Shared goals are not enough, and often the forum only held due to mandates instead of the common goals shared among stakeholder. This problem is typical in Indonesia's government institutions. Ultimately, the lack of collaboration in Infrastucture development in Indonesia can only be solved if the officials are aware of the problem and the potential solution from the real collaboration. As Ansell and Gash's (2007) realize that 
the collaborative governance will rely mostly on three key indicators which is, (1) time, (2) trust, (3) and interdependency. If the stakeholder were to realize the potential power of collaborative governance and start to collaborate with the acknowledgment that they will need time, trust, and the interpendencies. Infrastructure development in Indonesia will overcome its problem by eliminate the issues themselves due to the nature of collaborative governance itself. Indeed, it is long before we can conclude this, and more thorough research need to be done first if we are to be convince to implemented it in our system. On the other hand, we cannot ignore the potential of collaborative governance that believed by many scholars.

\section{Conclusion}

To get to convince the practition to regarding the collaborative governance and its potential used in infrastructure development in Indonesia will require more thorough research. In the other hand, the evidence of the general idea of collaborative governance pointed out that the syptoms of inefficient of infrastructure development in Indonesia are identified as related with key aspects of collaborative governance itself. Of this, we can put a believe that collaborative governance is one of worth solution regarding the issues of infrastructure development in Indonesia.

\section{References}

Agranoff, R. \& McGuire, M. (2003). Collaborative for Public Management: New Strategies for Local Governments. Washington DC: Georgetown University Press.

Ansell, C. \& Gash, A. (2007). Collaborative Governance in Theory and Practice. University of California. Journal of Public Administration Theory, 18(1), 543-571.

Forrer, J.J, Kee, J.E. \& Boyer, B. (2014). Governing Cross Sector Collaboration. San Fransisco: JoseyBass.

Purra, M. (2011). The Indonesian Electricity Sector: Institutional Transition, Regulatory Capacity and Outcomes. Infrasteucture Regulation: What Works, Why, and How Do We Know? World Scientific, 1(1) 231-278.

Zadek, S. (2006). The Logic of Collaborative Governance. Corporate Social Responsibility Initiative. Working Paper No. 17. 